\title{
Chicken Adaptability in Alternative Systems Adaptive Response of Chicken Strains to the Organic and Free Range Rearing Systems
}

\author{
Alice Cartoni Mancinelli ${ }^{1}$, Monica Guarino Amato ${ }^{2}$, David Meo Zilio ${ }^{2}$, Alessandro Dal Bosco ${ }^{1}$, Simona Mattioli $^{1}$ \\ and Cesare Castellini ${ }^{1}$
}

${ }^{1}$ Department of Agricultural, Environmental and Food Science University of Perugia, Italy

${ }^{2}$ Council for Agricultural Research and Economics, Livestock Production and Aquaculture, Italy

Submission: September 01, 2017; Published: November 10, 2017

*Corresponding author: Alice Cartoni Mancinelli Department of Agricultural, Environmental and Food Science University of Perugia, Via Borgo XX Giugno, 7406121 Perugia (Italy) Tel: 0039075-5857120-7121, Email: alicecartoni@hotmail.com

\begin{abstract}
The European Commission (EC) Regulation establishes that, in organic production (OP), the choice of breeds should take into account their capacity to adapt to local conditions, their vitality and their resistance to disease. Poultry genotypes are selected mainly for productive performance and thus fast growth rate. This kind of selection induced a decrease of the biodiversity in poultry species by causing the extinction of some native breeds and loss of genetic variability. Although there is a negative linear correlation between adaptation to OP and daily weight gain, the FG chickens are still used in OP. Based on these considerations, the aim of the present review was to address the adaptation of chicken strains in alterative systems.

The assessment of adaptability must be addressed with a multicriteria approach taking into account main aspects as: body weight, movement and foraging behaviour, animal welfare, immune response and also the effect of these factors on meat quality and environmental impact.

FG genotypes do not appear to be adapted to the outdoor environment as demonstrated by health problems (skeletal, cardiovascular) low movement and foraging behavior. Generally, SG birds are more suitable for OP in term of physiological adaptation, but sometime the productive performance is not adequate. Accordingly, further and new genotypes with a better balance between rusticity and productive performance would be necessary to enlarge OP diffusion. Use genotypes suitable for breeding systems improve animal welfare, enhance the quality of production and reduce the costs related to mortality and morbidity.
\end{abstract}

Keywords: Chicken; Adaptability; Organic production; Slow-growing strains; Fast-growing-strains.

\section{Introduction}

In the last century an enormous increase in poultry performance both for egg and meat production occurred. Average egg production increased from 176 eggs/hen/year in 1925 to 309 eggs/hen/year in 1998; on the other side, the days to produce 1500 grams of live gain decreased from 120 days in 1925 to 33 days in 1998 [1]. Nowadays, in European Union, the $95 \%$ of poultry production comes from intensive breeding systems, while the remaining $5 \%$ from organic (OP) and freerange production systems. The more common poultry genotypes sold to farmers can be divided into different groups according to their productive performance:

a. Selected hens with high egg deposition efficiency, used both in industrial production and alternative systems; b. Fast-Growing (FG) chickens: most of the chicken available in the stores today comes from flocks that rear the final weight in about 45 days;

c. Slow-growing (SG) chickens generally are chickens that can take almost twice as long to reach market weight-about 81 days typically.

There are also local breeds with a very slow performance (growth rate $<20 \mathrm{~g} /$ d) which could be used mainly in niche market and to maintain genetic biodiversity. The specialized strains cannot be used as dual-purpose animals (eggs and meat). In fact, the male of egg-type bird is comparable to a SG chickens whereas the egg productivity of female broiler is about $40 \%$ less than a specialized egg-type hens. 
The Article 12 of Regulation (EC) n. 889/2008 suggests that in organic livestock productions the choice of breeds should take into account their capacity to adapt to local conditions, their vitality and their resistance to disease. However, since the same regulation does not indicate the specific genotypes to use, often the farmer's choice is based only on productivity, so the most common animals used in organic systems are FG strains.

It is well known that FG chickens are not suitable to be reared in alternative systems where slaughtering age and use of outdoor run play an important role. In organic production a minimum slaughtering age is required (81 days). FG chichens, while having high performance, show a high level of mortality and poor health as demonstrated skeletal, muscular and cardiovascular problems; therefore, these chickens are not suitable for organic production. On the other hand, many SG chickens are not competitive as meat-type birds [2].

In this context, the best equilibrium among animal welfare, adaptability to extensive environment, biodiversity and productive performance should be found. In the last years, the increasing demand (still growing) for organic chickens can be an opportunity to develop new breeding techniques and the chicken strains more adapted to OP. The adaptation of chicken strains to alternative breeding systems must consider the following characteristics:

1. Productive performance (body weight and balance between different body parts);

2. Welfare and animal behaviour (movement, foraging);

3. Oxidative status, native immunity, blood parameters and use of pasture;

4. Product quality;

5. Environmental impact.

This review addresses the main traits that make a poultry genotype suitable for the extensive system and shows their close relationship.

\section{Productive performance (body weight and balance between different body parts)}

The main factors influencing the final body weight are the daily gain, in turn depending on feed consumption, feed efficiency and fat metabolism. Genetic selection has focused mainly on achieving commercial weight as soon as possible and on increasing breast weight, that is the more valuable muscle [3]. FG genotypes respond to that goal, so they are massively used in meat production. High productivity has a negative correlation on important traits such as animal welfare and meat quality and caused several issues [1]:

1. Fast-growth and feed conversion negative affect the lean/fat tissue ratio;
2. Efficiency of growth and feed conversion caused metabolic disorders; e.g. fast growth worse animal welfare and immune response.

3. Heavy breast weight causes a skeletal unbalance with severe effect on the stability of body and movement.

Body weight can be considered as an aggregate selection index of all the body components. Weight gain at a fixed age is mainly due to increased feed conversion efficiency, according to the "resource allocation" theory [4] most of the dietary energy is used in FG broilers for improving productive performance at the expense of the physiological functions. For this reason, the FG genotypes showed lower adaptability to OP compared to the SG ones (Figure 1), which result in metabolic disorders, such as heart failure syndrome etc. In addition, fast-growth caused a disproportion between muscle mass and internal organs, producing birds with relatively small respiratory and vascular systems.

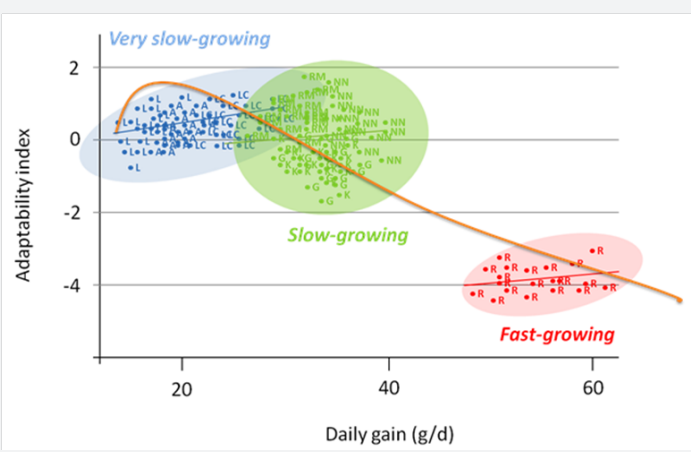

Figure 1: Correlation between an index of adaptation to extensive rearing system and daily growth. Modified from Castellini et al. [7].

This unbalance can also cause alterations in distribution of muscle fibre and in the ratio between capillaries and muscle fibres. The SG chickens shows fibre with lower area (Cross Sectional Areas - CSA) respect to the FG ones (2,546 vs $5,713 \mu \mathrm{m}^{2}$ ). The ratio number of fibre per microscopic field/ number of capillary is 2.0 vs 6.2 , respectively in FG and SG [5]. The higher CSA worsened the blood supply of the tissue and for this reason some FGs showed vascular problems with effect on muscle anomalies as giant fibres, necrosis and fibrosis myopaties [6].

\section{Welfare and animal behaviour (movement, foraging)}

The final recommendations of "Network for Animal Health and Welfare in Organic Agriculture (2002)" suggest that, in order to reduce the likelihood of welfare problems, the use of commercial breeds should be avoided, unless they have been tested and shown to work under organic conditions".

The main indicators of welfare in research studies are:

1. body lesions (foot-pad, breast-blister); 
2. feather conditions;

3. Tonic Immobility.

Dal Bosco et al. [7], comparing the behaviour of FG and SG in organic system, found that more than $70 \%$ of FG birds showed high level of footpad dermatitis whereas only $1.05 \%$ of SG one showed these lesions. Castellini et al. [8], studied adaptation to organic system of eight different chicken genotypes, confirming this trend. The SG chickens showed the best values in whole body regions as well as the absolute absence of footpad lesions and breast blister, while the $60 \%$ of FG birds had severe lesions score and worst feather conditions. In line with these results, Castellini et al [9] reported that SG showed a lower stress rate indicated by a better reactivity respect to FG (41sec vs. 110 sec of tonic immobility)

FG genotypes in free-range systems, stay indoors or near the house, rather than forage in the pasture. Dal Bosco et al. [7] used a GPS to detect the walking distance from poultry house and welfare of fast and SG genotypes. The data concerning the kinetic activity (Table 1 ) show that SG chickens covered an average daily distance of $1,230 \mathrm{~m}$, whereas FG birds only $125 \mathrm{~m}$. As a result, SG reached a higher distance from home and spent more time outdoors than FG.

Table 1: Global positioning system outcomes of organic chickens modified by Dal Bosco [7].

\begin{tabular}{|c|c|c|}
\hline Item & FG & SG \\
\hline Overall daily distance $\mathrm{m} / \mathrm{d}$ & 125 & 1230 \\
\hline Maximum distance from house, $\mathrm{m}$ & 25 & 100 \\
\hline Time spent outdoors, $\%$ & 25.6 & 74.9 \\
\hline Mean speed, $\mathrm{m} / \mathrm{h}$ & 8.93 & 95.71 \\
\hline
\end{tabular}

That response in FG genotypes is probably due to their high body weight and the related skeletal problems confirmed by welfare studies, showing an increase of culling and mortality rates when they were organically reared. In agreement with those observations, some authors showed that FG spend most of their time sitting on wet litter with breast and leg lesions results. Furthermore, sitting and lying in FG broilers increase with age: from $75 \%$ of the day in the first week to $90 \%$ at 5 weeks of age [10]. Other observations of broiler behaviour confirm that FG genotype had the worst results in terms of exploration interest and spent more time indoor than outdoor. Otherwise, the SG birds displayed a great variety of behaviour patterns and exploiting attitude in all the available pasture area.

Such outcome suggests that the genetic selection for a high growth rate has changed the behaviour of birds reducing energy expenditure for other than growing [11]. The SG genotypes have lower requirements for protein and energy than FG breeds [12], and spend more time foraging, walking and perching, whereas FG ones spent more time sitting, drinking and eating [13]. Rest and sleep are strongly associated with energy conservation, tissue restoration, and growth [14].
One of the basic aspects in alternative rearing systems is that animals have access to a free-range area, widely covered by grass, which encourages the chickens to exploration and then increase their movement

Enriched environments improve the outdoor exploration of animals. Many Authors $[15,16,17]$ showed that birds in reared systems without enrichment tended to stay indoors for a longer time rather than forage in the pasture; while, when pasture enrichments (sorghum or olive trees) are available, birds spent more time outdoors.

Pasture enrichment also affects the feed intake and the distance from shelter [16]: chickens reared under olive trees had higher herbage ingestion, exploring the available area up to 50 $\mathrm{m}$ from poultry house. The trees provided shelter and shadow to the chickens that, feeling protected by predator and high temperature, used the whole available pasture.

Kinetic activity is closely related to nutrition behaviour, the crop and gizzard contents of broiler strains with access to the pasture showed that SG birds had higher pasture intake than FG genotypes. Referring to foraging behaviour, FG birds never came out to the houses, making them organic in name only and suggesting that the environment provided is not a preferred habitat [17]. Accordingly, Castellini et al. [18] showed that SG crop content was rich in grass and then in bioactive compounds ( $\alpha$-tocopherol and carotenoids), which, improved the birds antioxidant capacity and balance the lipid oxidation (TBARS) compared to the FG one. This better oxidative response in SG counteracted the production of free radicals (reactive oxygen species - ROS and reactive nitrogen species -NOS) due to the higher motor activity. The Regulation for organic agriculture of European Union prohibit the use of synthetic antioxidants in the OP, for this reason the animal's grazing capacity becomes crucial to supply these compounds by themselves. In conclusion, animal behavior is an important topic for characterizing the interactions between birds and their environment; in this case, the organic rearing system does not reduce welfare problems of FG birds.

\section{Oxidative status, native immunity, blood parameters and use of pasture}

The in vivo (blood) oxidative status of chickens is a complex process where various antioxidants and pro-oxidants come into play (Figure 2). Antioxidants can be incorporated into the body through the diet. The grass is rich in antioxidant compounds, so the foraging behavior of the chicken influences the oxidative state of the animal [19]. As mentioned above, this behavior is closely related to the movement of the birds. The kinetic activity of birds increases the demand for oxygen and consequently raises the level of ROS in blood plasma and tissues. ROS have a pro-oxidant action mainly on polyunsaturated fatty acids (PUFAs). However, in a live system, the stabilization of fatty acids is ensured by the presence of tocopherols, carotenoids and other bioactive substances taken by the grass that in such way counteracts oxidation processes [20]. 


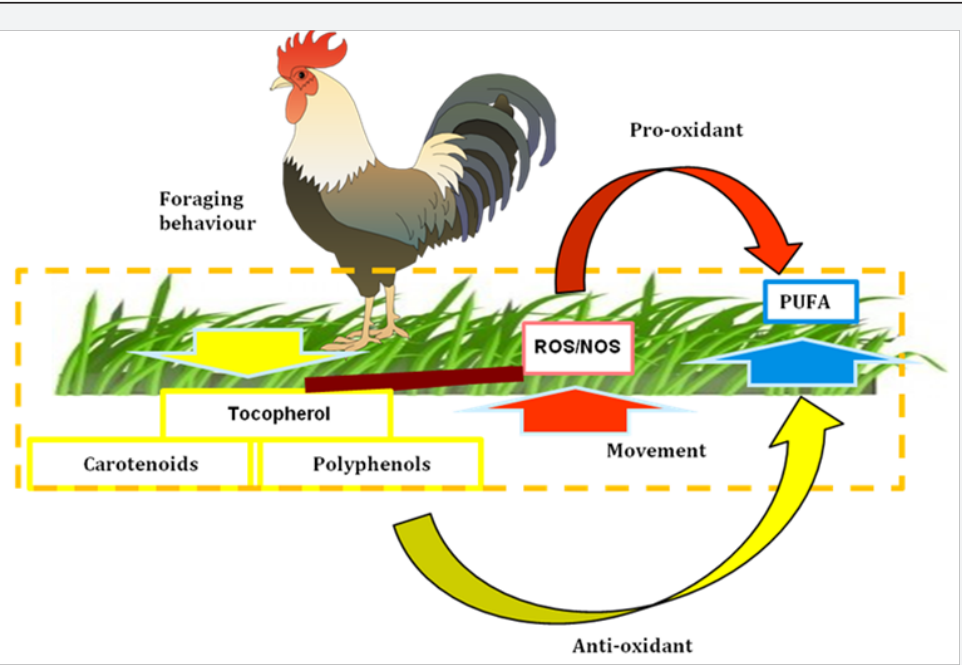

Figure 2: Oxidative balance in relation to nutrition behavior and movement in chicken.

It is well known that SG have a greater ability to movement than the FG one, consequently many authors have found a higher values of ROS and $\alpha$-tocopherol in plasma in SG respect to FG [8]. Mattioli et al [21] compared the effect of moderate locomotory activity (induced and prolonged) on the blood oxidative status in FG and SG genotypes. During the experimental period, the SG strain exhibited an adaptive response to exercise with a progressive improvement in the oxidative values due to the body training (low ROMS and TBARS). On the contrary, the control FG birds had a lower ROMS and TBARS, but they showed an inadequate response to the free radical production induced by locomotory activity, and the body antioxidant status progressively worsened.

A strong relationship could be found among welfare, immunity and health, as reported by many Authors [22,23]. Behaviour plays an important role in disease transmission, and at the same time, diseases have effects on the evolution of behaviour. Other studies $[24,25]$ showed that animals are more susceptible to infection when they live in a poor environment, fed a poor diet and/or are under physical or psychological stress.

Regarding the immune response, it should be pointed out that generally extensive rearing systems require adequate level of immune response due to the high environmental pressure. Many Authors in different species found that the more selected breeds show a lower immune response [26-28]. The activation of the immune system is energetically expensive, thus, FG birds, which are genetically selected for high production, would be less capable of coping with environmental stress.

\section{Productive quality}

The quality of chicken meat should be the result of an adaptation response to a certain breeding system. In addition, the genotype and the age at slaughtering affect the meat quality parameters. Fanatico et al. [29], feeding the same diet to SG and
FG birds for 81 and 53 days, respectively, observed that SG birds had the highest drip and cooking losses and tougher meat. One of the main nutritional parameters affected by the farming system is the meat oxidative status [30].

The motor activity of chickens, induced modifications on muscle fiber characteristics and enzyme functions only in animals adapted to the organic system [6]. The pasture availability increased the vitamins and xantophylls contents in the yolk egg [31] as well as the unsaturated fatty acids content, at the same time improved the albumen and shell quality [32].

The previously mentioned vitamin E intake of chickens, thought the grass, enhances the muscle accumulation of $\alpha$-tocopherol (the main isomer of vitamin E), which protects against oxidation and extends the shelf-life of the product. Furthermore the grass contains a large amount of PUFA (e.g. $\alpha$-linolenic acid), which could be further metabolized into meat and egg. This high level of PUFA, although nutritional beneficial, have a negative effect on oxidative stability.

Chicken meat quality is strongly affected by genotype, many behavioral and physiological differences arise from the comparison of SG with FG strains [33]. Castellini et al. [8] show a higher concentration of PUFA n-3 series in SG meat respect to the FG ones. Meat of SG, compared to FG, generally has high concentration of PUFA and in particular of PUFA n-3 series, which improves the nutritional value. In agreement, Meluzzi et al. [34] showed a lower ratio n-6/n-3 on SG meat than FG in organic rearing system.

Sirri et al. [35] demonstrated that SG meat had a lower proportion of monounsaturated fatty acids (MUFA) $(22.82 \%$ vs. $30.91 \%)$ and amounts equal to double PUFA n-3 (8.7\% vs $5.14 \%$ ) compared to FG. In this study the large differences in the fatty acid composition of the meat among genotypes it was attributed mainly to the genotype rather than feeding, since all 
the birds received the same diets. However, despite the higher intake of antioxidants ( $(3)$, meat of SG birds generally have a worse oxidative stability (lipid oxidation) related to the high kinetic attitude and higher PUFA amount.

Castellini et al [36] investigated the influence of preslaughter transport length in different genetic strains. The stress transport negatively affected the meat oxidation status (TBARS value), with a decreased of antioxidant compounds (vitamins E, A and xanthophylls) important in terms of product shelf-life. This study shows that the SG chickens, being animals more active, seem more sensible to stress transport due to their higher movement before slaughter. A balance between PUFA enrichment, movement and oxidative stability should be found by managing the feed and the slaughtering processes, which in $\mathrm{SG}$ is generally more stressful.

\section{Environmental impact}

The use of FG or SG strains also affects the environmental impact.

Boggia et al. [37] used the Life Cycle Assessment analysis in order to compare three different poultry rearing systems:

1. Conventional, using FG bred indoor,

2. Organic, that uses SG bred with outdoors space $\left(4 \mathrm{~m}^{2} /\right.$ bird),

3. Organic-plus, similar to the Organic. But with greater availability of outdoor space $\left(10 \mathrm{~m}^{2} /\right.$ bird).

Organic systems are generally associated with an ecological production and environmental sustainability [38], but the results of this study showed the opposite. One of the main reasons is the dispersal of animals in the outer area: if the animals stay close in the houses (in the case of FG) and do not extend fall to the pasture, there is a concentration of pollution ( $\mathrm{N}$ and $\mathrm{P}$ ) in a small portion of ground. However, the global environmental impact also depends on the efficiency of fodder conversion, which is very favorable in FG vs SG (3.0 vs. 4.0) birds.

Use a multicriteria approach that combined economic, social, qualitative and environmental indicators into the many dimensions of sustainability allowed a more complete evaluation of different poultry farming systems [38]. Energy evaluation [39] is a tool particularly suitable to this task because it deals at best with systems at the interface between the "natural" and the "human" spheres [40] and it is able to account for all the inputs on a common basis, avoiding difficulties and subjectivity that could take place with other methods [41]. The comparison of an organic poultry farm with a conventional one with Emergy showed that organic system was more sustainable than the conventional [42]. Therefore, to reach equilibrium among all of the dimensions considered it is necessary to find a production system and a suitable genotypes that conciliates them into one coherent scheme.

\section{Conclusions}

In conclusion it is necessary that chickens maintain a certain level of productivity that coordinates all these factors (environmental, animal welfare and meat quality) in sustainable system which will be investigated with the application of "multicriteria analysis" [37].

SG genotypes are more adapted to organic and free-range systems because there is a negative correlation between grow rate and adaptability. However, within the same sub-group (SG and $\mathrm{FG}$ ); there is a different degree of adaptation to organic system. In fact, chicken strains with similar weight gains can show wide variations in the adaptation.

The problem of finding a genotype suitable for alternative systems remains unresolved. For this reason, further studies are needed to achieve a compromise between adaptability and productive performance.

\section{Conflict of Interest}

I declare that I do not have any conflict of interest

\section{References}

1. Decuypere E, Bruggeman V, Barbato G, Buyse J (2003) Growth and reproduction problems associated with selection for increased broiler meat production, in Poultry Genetics, Breeding and Biotechnology. Muir W \& Aggrey S (Eds.), CABI Publishing, Wallington, pp 13-28.

2. Castellini C, Mugnai C, Dal Bosco A (2002) Effect of organic production system on broiler carcass and meat quality. Meat sci 60(3): 219-225.

3. Emmerson DA (1997) Commercial approaches to genetic selection for growth and feed conversion in domestic poultry. Poult Sci 76(8): 11211125.

4. van der Waaij EH (2004) A resource allocation model describing consequences of artificial selection under metabolic stress. Journal of Animal Science 82(4): 973-981.

5. Monica S, Porcellato I, Branciari R, Ranucci D, Mattioli S et. al (2017) Morphological evaluations of pectoralis major muscle in two chicken strains. $22^{\text {nd }}$ Congress of ASPA, Perugia, Italy.

6. Branciari R, Mugnai C, Mammoli R, Miraglia D (2009) Effect of genotype and rearing system on chicken behavior and muscle fiber characteristics. J Anim Sci 87(12): 4109-4117.

7. Dal Bosco A, Mugnai C, Sirri F, Zamparini C, Castellini C (2010) Assessment of a global positioning system to evaluate activities of organic chickens at pasture. Journal of Applied Poultry Research 19(3): 213-218.

8. Castellini C, Mugnai C, Moscati L, Mattioli S, Guarino AM, et al. (2016) Adaptation to organic rearing system of eight different chicken genotypes: behavior, welfare and performance. IJAS 15(1): 37-46.

9. Castellini C, Dal Bosco A, Mugnai C, Bernardini M (2002) Performance and behavior of chickens with different growing rate reared according to the free-range system. Ital J Anim Sci 1: 291-300.

10. Bessei W (1992) Das Verhalten von Broilern unter intensiven Haltungsbedingungen. Arch Geflugelkd 56(1): 1-7.

11. Schutz KE, Jensen P (2001) Effects of resource allocation on behavioral strategies: A comparison of red junglefowl (Gallus gallus) and two domesticated breeds. Poult Ethol 107(8): 753-762. 
12. Bellof E, Schmidt E (2005) Broiler production with $100 \%$ organic feed is possible, In: Hess J et al. (Eds.), Proceedings of the $8^{\text {th }}$ Conference on Organic Farming, University of Kassel, Germany, Kassel University press GmbH, Germany, pp. 321-324.

13. Bokkers EAM, Koene P (2003) Behaviour of fast- and slow growing broilers to 12 weeks of age and the physical consequences. Applied Animal Behaviour Science 81: 59-72.

14. Blokhuis HJ (1983) The relevance of sleep in poultry. Worlds Poult Sci J 39(1): 33-37.

15. Sossidou EN, Rose SP, Hall NW, Tserveni-Goussi A (2010) Effects of composted vegetable waste as soil medium in free-range laying hens' production systems on birds' behavior, soil structure, grass cover and nematode population. Archiv für Geflügelkunde 74(2): 81-86.

16. Dal Bosco A, Mugnai C, Rosati A, Paoletti A, Caporali S, et al. (2014) Effect of range enrichment on performance, behavior, and forage intake of free-range chickens. Journal of Applied Poultry Research 23(2): 137 145.

17. Dawkins MS, Cook PA, Whittingham MJ, Mansell KA, Harper AE (2003) What makes free-range broiler chickens range? In situ measurement of habitat preference. Animal Behaviour 66: 151-160.

18. Castellini C, Mugnai C, Pedrazzoli M, Dal Bosco A (2006) Productive performance and carcass traits of Leghorn chickens and their crosses reared according to the organic farming system. In Atti XII European Poultry Conference, Verona, Italy, 10-14.

19. Sossidou EN, Dal Bosco A, Castellini C, Grashorn MA (2015) Effects of pasture management on poultry welfare and meat quality in organic poultry production systems. World's poultry science journal 71(2): 375-384.

20. Mugnai C, Dal Bosco A, Moscati L, Battistacci L, Castellini C (2011) Effect of genotype and husbandry system on blood parameters, oxidative and native immune status: welfare and implications on performance of organic laying hens. The Open Veterinary Science Journal 5: 12-18.

21. Mattioli S, Dal Bosco A, Ruggeri S, Martino M, Moscati L, et al. (2017) Adaptive response to exercise of fast-growing and slow-growing chicken strains: Blood oxidative status and non-enzymatic antioxidant defense. Poult Sci 96(11): 4096-4102.

22. Padgett DA, Glaser R (2003) How stress influences the immune response. Trends Immunol 24(8): 444-448.

23. Broom DM (2006) Behaviour and welfare in relation to pathology. Appl Anim Behav Sci 97: 71-83.

24. Humphrey T, O’Brien S, Madsen M (2007) Campylobacters as zoonotic pathogens: a food production perspective. Int J Food Microbiol 117(3): 237-257.

25. Maxwell MH (1990) Hematological and histopathological findings in young broilers reared in poorly and well ventilated environments. Res Vet Sci 48(3): 374-376.

26. Franciosini MP, Bietta A, Moscati L, Battistacci L, Pela M, et al. (2011) Influence of different rearing systems on natural immune parameters in broiler turkeys. Poult Sci 90(7): 1462-1466.

27. Nath M, Singh BP, Saxena VK, Roy AD, Singh RV (2002) Estimation of crossbreeding parameters for serum lysozyme level in broiler. Asian Australasian Journal of Animal Sciences 15(2): 166-171.
28. Altan O, Altan A, Cabuk M, Bayraktar H (2000) Effects of heat stress on some blood parameters in broilers. Turkish J Anim Sci 24: 145-148.

29. Fanatico AC, Cavitt LC, Pillai PB, Emmert JL, Owens CM (2005) Evaluation of slower-growing broiler genotypes grown with and without outdoor access: meat quality. Poult Sci 84(11): 1785-1790.

30. Lewis PD, Perry GC, Farmer LJ, Patterson RLS (1997) Responses of two genotypes of chicken to the diets and stocking densities typical of UK and label rouge production systems: I. performance. Behavior and carcass composition. Meat Sci 45(4): 501-516.

31. Mugnai C, Dal Bosco A, Castellini C (2009). Effect of rearing system and season on the performance and egg characteristics of Ancona laying hens. Ital J Anim Sci 8(2): 175-188.

32. Hammershøj M (1997) Effect of dietary vegetable oils for egg layng hens on yolk fatty acid composition and other quality traits in phase feeding programme. In: Proc. VII Euro. Symp. on the Quality of eggs and egg products Poznan, Poland. Hammond, J Objective tests for quality in meat. Ann Nutr.

33. Castellini C, Dal Bosco A, Mugnai C, Pedrazzoli M (2006) Comparison of two chicken genotypes organically reared: oxidative stability and other qualitative traits of the meat. Ital J Anim Sci 5(1): 29-42.

34. Meluzzi A, Sirri F, Castellini C, Roncarati A, Melotti P et al. (2009) Influence of genotype and feeding on chemical composition of organic chicken meat. Ital J Anim Sci, 8(sup2): 766-768.

35. Sirri F, Castellini C, Bianchi M, Petracci M, Meluzzi A et al. (2011) Effect of fast, medium-and slow-growing strains on meat quality of chickens reared under the organic farming method. Animal 5(2): 312-319.

36. Castellini C, Mattioli S, Piottoli L, Cartoni MA, Ranucci D, et al. (2016) Effect of transport length on in vivo oxidative status and breast meat characteristics in outdoor-reared chicken genotypes. Ital J Anim Sci 15(2): 191-199.

37. Boggia A, Paolotti L, Castellini C (2010) Environmental impact evaluation of conventional, organic and organic-plus poultry production systems using life cycle assessment. WPSJ 66(1): 95-114.

38. Castellini C, Berri C, Le Bihan-Duval E, Martino G (2008) Qualitative attributes and consumer perception of organic and free-range poultry meat. Worlds Poult Sci J 64(4): 500-512.

39. Castellini C, Boggia A, Cortina C, Dal Bosco A, Paolotti L, et al. (2012) A multicriteria approach for measuring the sustainability of different poultry production systems. J Clean Prod 37: 192-201.

40. Odum HT (1996) Environmental accounting: Energy and Environmental Decision Making. Wyley \& Sons, New York, USA, p. 370

41. Bakshi BR (2002) A thermodynamic framework for ecologically conscious process systems engineering. Comput Chem Eng 26(2): 269282.

42. Castellini C, Bastianoni S, Granai C, Dal Bosco A, Brunetti M (2006) Sustainability of poultry production using the energy approach: Comparison of conventional and organic rearing systems. Agric Ecosyst Environ 114(2): 343-350. 
This work is licensed under Creative

Commons Attribution 4.0 Licens

DOI: 10.19080/JDVS.2017.04.555644
Your next submission with Juniper Publishers will reach you the below assets

- Quality Editorial service

- Swift Peer Review

- Reprints availability

- E-prints Service

- Manuscript Podcast for convenient understanding

- Global attainment for your research

- Manuscript accessibility in different formats

( Pdf, E-pub, Full Text, Audio)

- Unceasing customer service

Track the below URL for one-step submission https://juniperpublishers.com/online-submission.php 